DOI - https://doi.org/10.5965/2316796310202021045

\title{
USABILIDADE COMO FATOR DE ADOÇÃO DE BANCAS DIGITAIS POR LEITORES ANALÓGICOS
}

\section{USABILITY AS AN ADOPTION FACTOR OF DIGITAL STANDS BY ANALOG READERS}

Bruno Cavalheiro Bertagnolli 7

Gabriela Botelho Mager ${ }^{2}$ 


\section{Resumo}

Dados recentes do mercado editorial de revistas mostram que $82 \%$ dos leitores consomem apenas versão impressa. Considerando a usabilidade como um fator de adoção de produtos digitais, a pesquisa analisa qual impacto de requisitos relacionados às metas de desempenho e satisfação do usuário na percepção de uso de uma banca digital partindo-se da percepção de leitores exclusivamente analógicos. O estudo exploratório e descritivo é resultado de um processo de avaliação de usabilidade onde foram analisados 4 parâmetros relacionados à meta de desempenho e 9 parâmetros relacionados à meta de satisfação. Os resultados apontam que usuários de faixas etárias mais jovens são mais críticos e fatores relacionados a desempenho não afetam a percepção de qualidade de uso. Por outro lado, os fatores Esforço, Tela e Terminologia (ligados à meta de satisfação) tiveram maior impacto na percepção positiva de uso. Conclui-se que os leitores analógicos desejam um sistema de banca digital mais funcional que possibilite uma melhor transição para a mídia digital. Os apontamentos podem ajudar a melhorar a qualidade da interface de sistemas similares atendendo melhor as necessidades de usuários adotantes de plataformas digitais de leitura.

Palavras-chave: banca digital; revista digital, usabilidade; migração digital.

\section{Abstract}

Recent data from the magazine publishing market show that $82 \%$ of readers consume only the print version. Considering usability as a factor in the adoption of digital products, the research analyzes the impact of requirements related to performance and user satisfaction goals on the perception of use of a digital newsstand, starting from the perception of exclusively analog readers. The exploratory and descriptive study is the result of a usability evaluation process where 4 parameters related to the performance goal and 9 parameters related to the satisfaction goal were analyzed. The results show that users of younger age groups are more critical and performance-related factors do not affect the perception of quality of use. On the other hand, the Effort, Screen and Terminology factors (linked to the satisfaction goal) had a greater impact on the positive perception of use. It is concluded that analog readers want a more functional digital newsstand system that allows for a better transition to digital media. Notes can help improve the interface quality of similar systems, better meeting the needs of users adopting digital reading platforms.

Key-words: digital newsstand; digital magazine, usability; digital migration.

\footnotetext{
1 cb.bruno@gmail.com

2 gabrielamager@gmail.com
} 


\section{INTRODUÇÃO}

A digitalização dos meios impressos de comunicação trouxe novos hábitos e mais possibilidades na forma de consumir informação, como no caso das revistas onde há a coexistência de suportes, adicionando ao físico suas respectivas versões digitais e seus agregadores de edições, como por exemplo bancas digitais (FREIRE, 2016). Diferente de outros produtos editoriais já digitalizados, dados de mercado apontam para uma queda geral de circulação de títulos (GRUPO DE MÍDIA SÃO PAULO, 2020; MEIO \& MENSAGEM, 2018a; MEIO \& MENSAGEM, 2018b), o que tem levado o setor de revistas a uma crise em nível mundial - demonstrando que o formato digital precisa ser analisado buscando sua consolidação.

Como saída para todo esse contexto, Shirley (2015, apud PENTEADO 2015), coloca que o meio revista precisa desenvolver estratégias que fortaleçam os vínculos de interatividades com seus leitores, tendo a capacidade e habilidade de migrar para o meio digital sem perder credibilidade, pertinência e relevância dos leitores.

Isso demonstra a importância do meio digital como plataforma de sobrevivência da revista, devendo-se analisar os caminhos para adoção e popularização em tal suporte. Uma das abordagens nesse caso é a relação produto-usuário pelo prisma da interação com a interface, que deve ser amigável e intuitiva, que conforme Lévy (1999, p. 39), a qualidade dos suportes de exibição ou de saída da informação é determinante para os usuários dos sistemas de computadores e condiciona em grande parte seu sucesso prático e comercial. A usabilidade neste contexto pode assim ajudar a medir e traduzir aspectos essenciais da experiência do usuário ao interagir com o produto por meio de métricas variadas (TULLIS; ALBERT, 2013), mostrando seu impacto sobre a migração de leitores analógicos para o formato digital no caso de revistas. Entender a visão do usuário nesse processo de transformação é significante para o futuro da área editorial, o que pode responder diversos questionamentos sobre a transição de suporte. A usabilidade pode influenciar a experiência de uso de produtos e definir seu sucesso, logo a análise dos fatores que podem impactar o uso da revista digital pode indicar os esforços necessários para a construção ou melhoria de bancas e sistemas mais adaptados ao usuário, beneficiando o mercado editorial e seus diversos atores.

A literatura apresenta diversos estudos que usam a usabilidade para explorar produtos editoriais digitais como jornais, revistas e livros (AKOUR, ADAMS, 2017; NADZIR et al, 2019; FENSTERSEIFER et al., 2016), a maioria buscando levantar problemas de interface de títulos específicos, no entanto não se encontram estudos relacionando usabilidade no contexto de adoção de bancas digitais e suas revistas por usuários analógicos.

Este artigo propõe analisar como o critérios de usabilidade definidos a partir da literatura e ligados as metas do usuário (Desempenho: Sucesso na tarefa; Nível de sucesso na tarefa; Eficiência relativa; Nível de eficiência e Aprendizagem; Satisfação: Comentários; Expectativa antes e após o uso; Utilidade; Atratividade; Uso futuro; Esforço de utilização; Tela; Terminologia; Capacidade do sistema e Satisfação geral) impactam na percepção de uso de banca digitais a partir da visão de leitores de mídia impressa. O objetivo é verificar como tais fatores podem vir a influenciar para que um leitor analógico adote a plataforma digital de leitura. 


\section{REVISTAS E BANCAS DIGITAIS E O MERCADO ATUAL}

Entende-se como edição digital de revista a cópia da publicação impressa que foi distribuída eletronicamente como uma unidade (INSTITUTO VERIFICADOR DE CIRCULAÇÃO, 2017). Uma edição digital pode ser caracterizada como uma simulação, pois imita o funcionamento análogo de um objeto físico, a revista impressa. Com a maior oferta de títulos nesse formato surgiu naturalmente a necessidade de encontrar meios de organizá-los e distribuí-los, dando início às plataformas agregadoras conhecidas como "bancas digitais". Tais sistemas oferecem acesso multiplataforma, agregam e comercializam edições atuais e anteriores, oferecem ferramentas de busca, leitura, download, diversos recursos de navegação, sendo uma solução para distribuição digital (SIVEK; TOWNSEND, 2014).

A migração do conteúdo editorial para os suportes digitais objetiva a redução dos custos de fabricação e distribuição, seguindo a tendência de maior oferta e consumo de produtos e serviços online, mas no Brasil $82 \%$ dos leitores de revista ainda consomem apenas edição impressa, $11 \%$ consomem edição impressa e digital e 7\% apenas versão digital (ASSOCIAÇÃO NACIONAL DOS EDITORES DE REVISTAS, 2015), podendo-se dizer assim que a revista ainda encontra-se no processo transicional de suporte ao longo dos últimos anos. Isso é demonstrado pelo lento aumento da circulação de alguns títulos digitais desde 2010 - ano que marcou a estreia online dos principais títulos para venda avulsa ou assinatura (figura 1).

Figura 1: Comparativo da circulação média anual impressa e digital de títulos pagos (por edição) entre 2010 e 2019

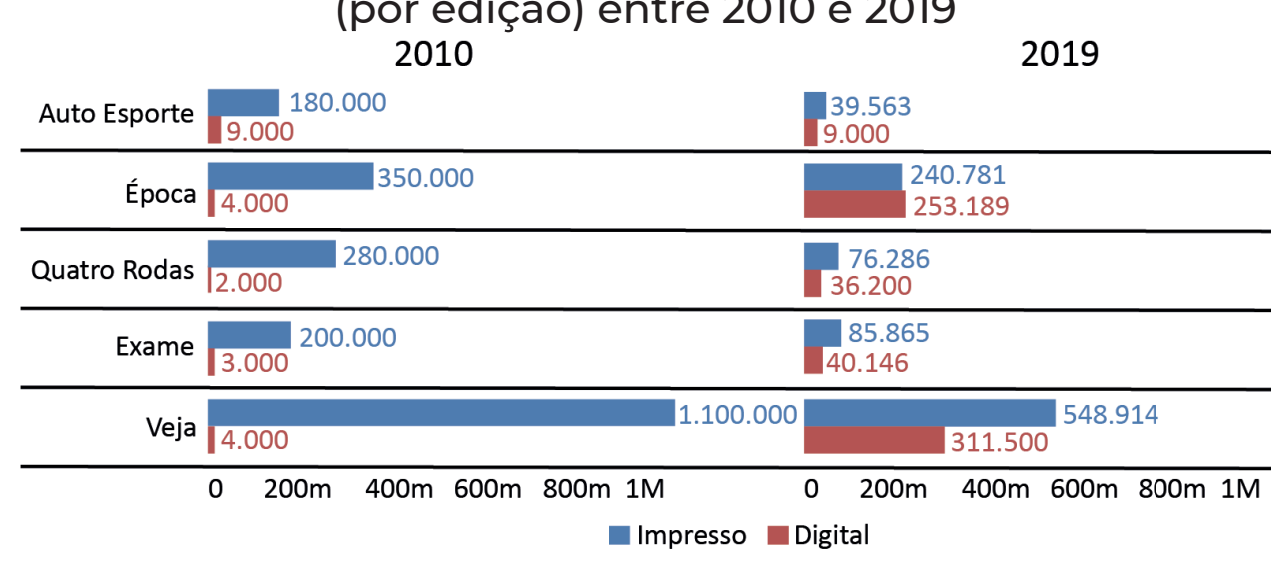

*Pelas regras do IVC: um download pago $=1$ unidade digital vendida.

**Revista Veja: tiragem semanal; demais títulos: tiragem mensal.

Fonte: Associação nacional dos editores de revistas (2015); Grupo de Mídia São Paulo (2017) e sites das editoras.

Observa-se que embora a circulação digital tenha crescido expressivamente ao longo dos anos, em 2019 ainda estava abaixo do impresso na maioria dos casos. Percebe-se também a queda geral na circulação de títulos, não compensada pelo aumento da circulação digital, possivelmente influenciada pela concorrência com outras fontes gratuitas e online de informação.

Todo esse contexto tem desencadeado uma crise do mercado editorial de revistas que atingiu grandes editores nacionais (e também internacionais), os quais têm 
continuamente cancelado títulos devido à desestruturação logística e financeira do atual processo de distribuição. Isso demonstra a importância do meio digital como plataforma de sobrevivência da revista, devendo-se analisar os caminhos para sua adoção e popularização.

Considerando assim a revista e a banca digital como produtos tecnológicos ainda em consolidação, a usabilidade é um fator que entre outras finalidades pode vir a potencializar uma oferta mais adequada às necessidades dos usuários-leitores.

\section{USABILIDADE E SUAS MÉTRICAS}

A usabilidade é resultado do uso de uma ferramenta em um contexto particular (considerando o usuário, tarefas, ambientes físicos e organizacionais) assumindo que a qualidade em uso pode ser medida a partir da interação com tais ferramentas, levando em conta se os objetivos do usuário são alcançados com o gasto apropriado de recursos (por exemplo tempo e esforço mental) e de forma satisfatória (CYBIS; BETIOL; FAUST, 2015).

Tullis e Albert (2013) propõem que a usabilidade seja vista pelo prisma de dois aspectos principais da experiência do usuário: as metas de desempenho (tudo sobre o que o usuário realmente faz na interação); e as metas de satisfação (o que o usuário diz ou pensa sobre sua interação com o produto).

Os fatores de usabilidade são atributos orientados ao usuário ou características da interface do usuário. Na literatura são diversas as referências a estes fatores, embora muitos possuam correspondência ou podem ser agrupados em categorias semelhantes. Uma abordagem utilizada para a construção de métricas que medem usabilidade é a GQM (Goals, Questions and Metrics) proposta por Basili, et al. (1994), que segue os princípios do paradigma da "avaliação orientada por objetivos". Esse modelo busca servir como uma metodologia genérica para orientar a elaboração e execução de programas de avaliação da qualidade de produtos digitais como softwares.

Donyaee et al. (2006) colocam que os dados são usados para calcular as métricas, existindo diferentes métodos para extraí-los por meio de procedimentos (testes de usabilidade) que averiguam a interação de usuários com sistemas.

\section{MATERIAIS E MÉTODOS}

A pesquisa aplicada proposta é exploratória e de cunho quali-quantitativa, e buscou através de métodos de avaliação de usabilidade responder ao problema de pesquisa de acordo com a seguinte estrutura:

(a) Levantamento bibliográfico sobre temas diretamente ligados ao estudo;

(b) Estruturação das etapas e técnicas avaliativas através do framework D.E.C.I.D.E. (PREECE; ROGERS; SHARP, 2019) (detalhado nos tópicos 4.1 ao 4.6) e com base no plano de teste sugerido por Rubin e Chrisnell (2013);

(c) Aplicação de teste de usabilidade com usuários para coleta de dados (1. Questionário pré-teste, 2. Execução de tarefas, 3. Questionário pós-tarefas e 4. Entrevista);

(d) Análise dos resultados das avaliações;

(e) Discussão e conclusão da pesquisa.

A banca digital GoRead da editora Abril foi escolhida como objeto de estudo (Figura 2) por sua relevância no mercado nacional e trazer os títulos de maior circulação. 
O suporte utilizado foi o computador, seguindo os dados de pesquisas que indicam o dispositivo como o mais utilizado para consumo de conteúdo editorial e por leitores de revistas digitais.

Figura 2: Telas da banca digital GoRead

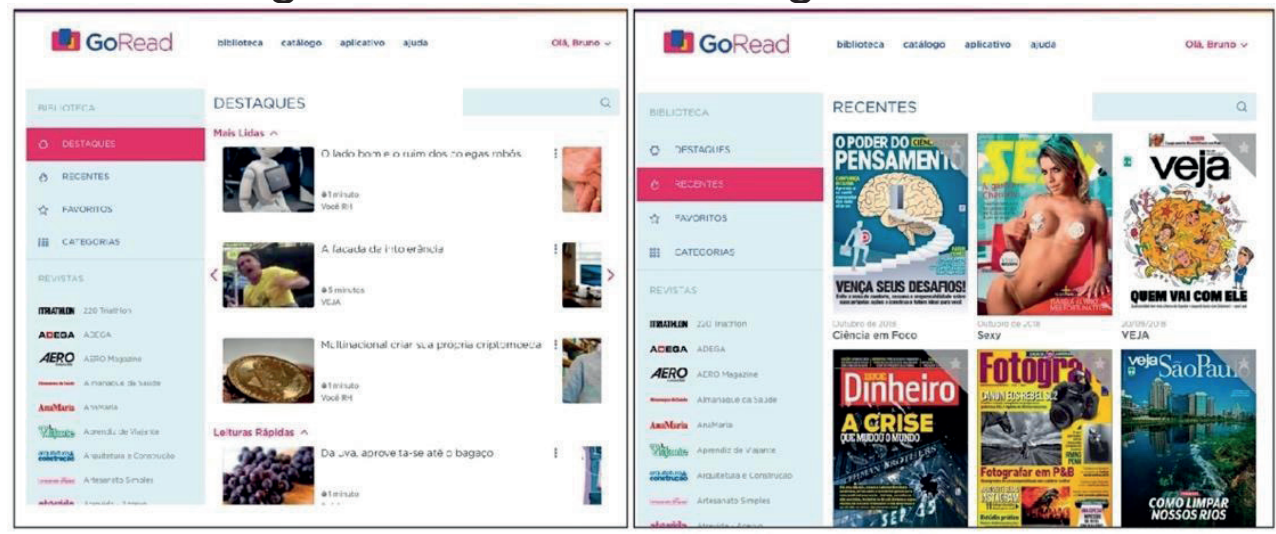

Fonte: Captura de tela da Banca digital GoRead / Editora Abril.

\subsection{Determinar os objetivos gerais a serem abordados na avaliação}

O propósito global da avaliação foi explorar o impacto da usabilidade na percepção da qualidade de uso da banca digital que poderia levar um usuário analógico a adotá-la, sendo seu objetivo obter (a partir da perspectiva dos usuários) dados relacionados aos critérios de usabilidade possibilitando demonstrar como cada um impacta a experiência de uso podendo contribuir para a adoção do produto, respondendo ao problema de pesquisa.

\section{2 Explorar as Questões}

Partindo-se do objetivo geral, elaboraram-se perguntas específicas a serem respondidas com a avaliação. A abordagem GQM (BASILI et al., 1994) foi utilizada para estruturar essa etapa, sendo as metas de desempenho e satisfação o ponto de partida. A partir disso quinze questões focadas na usabilidade e suas respectivas métricas foram definidas de forma a responder ao problema de pesquisa (Figura 3). A definição das métricas foi feita com base em revisão de literatura sobre o tema. 
Figura 3: Metas, critérios e métricas utilizadas.

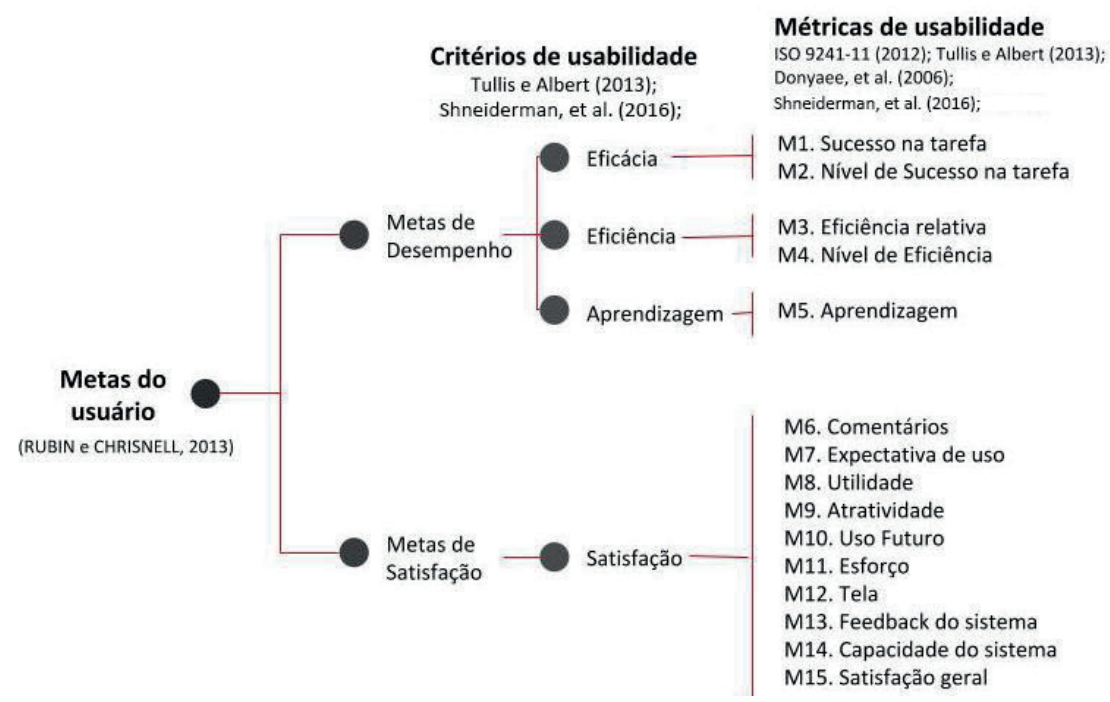

Fonte: Autor.

\subsection{Escolher o paradigma de avaliação}

O paradigma principal que norteou o estudo foi o teste de usabilidade com usuários na forma de estudos de campo, pois a diretriz das avaliações era que fossem realizadas no local indicado pelo usuário, tentando simular a utilização do sistema de forma natural. Considerando o objetivo geral e as perguntas de pesquisa, relacionaram-se às questões de usabilidade com as métricas (variáveis), a forma de medi-las e como obtê-las (métodos). Assim para a coleta de dados seguindo as métricas definidas (conforme a figura 3) definiram-se como métodos:

(1) Questionário pré-tarefas: Seu objetivo principal era assegurar o perfil da amostra (pelos critérios de inclusão e exclusão definidos) por meio de questões sobre faixa etária, sexo, profissão, experiência com computadores e uso de internet. Sobre perfil de consumo de revistas impressas questionou-se a forma de compra; gênero, frequência e local de leitura; além do conhecimento sobre a existência de banca e revista em versões digitais. Coletou-se também dados da métrica M7 (Expectativa antes do uso)

(2) Execução de tarefas: Tinha o objetivo de medir as métricas de desempenho, de M1 a M5, permitindo experiência de uso para que fossem respondidos outros questionamentos. Definiram-se 5 cenários-tarefas independentes, mas interligados dentro de um percurso representativo do uso típico do produto por um usuário padrão, buscando explorar os principais recursos do sistema e cobrindo as métricas definidas (tabela 1): 
Tabela 1: Cenários e tarefas para coleta de dados de uso.

Cenário Geral: Imagine que você está em um momento de lazer, já é assinante do produto e quer utilizar a banca para ler algumas revistas no computador. Cenários-Tarefas:

Cenário 1: Imagine que você está planejando uma viagem para o final do ano, e por isso quer encontrar a última edição da revista "Viagem" para ler com calma mais tarde. Tarefa 1: Encontrar a última edição da revista "Viagem" e marcá-la como favorita para ler mais tarde.

Cenário 2: Agora você quer ler a última edição da revista "Superinteressante", pois ouviu falar que a matéria de capa deste mês falava de um assunto de seu interesse. Tarefa 2: Encontre a capa da última edição da revista "Superinteressante" na banca.

Cenário 3: Você achou a revista Superinteressante e quer ler a matéria de capa. Tarefa 3: Navegue até a matéria estampada na capa (fim da tarefa). Sub tarefa de tempo livre: Leia o primeiro parágrafo da matéria para ter a experiência da leitura em tela.

Cenário 4: Imagine que você já leu toda a revista Superinteressante e quer ler a revista "Viagem" que você marcou como favorita logo que entrou na banca. Tarefa 4: Encontre na banca a revista "Viagem", marcada como favorita na tarefa 1.

Cenário 5: Imagine que está com tempo livre, explorando novas publicações na banca sobre a área de Carreira. Tarefa 5: Procure na categoria "Carreira \& Negócios" a revista "Você RH" deste mês.

Tarefa livre: Explore o produto de forma livre, mas com foco na interface. Fonte: Autor.

Adicionou-se ao final dos testes tempo ( $2 \mathrm{~min}$ ) para livre exploração do produto, de forma a permitir que o usuário tivesse uma melhor percepção e contato antes de responder ao questionário com as questões sobre satisfação.

(3) Questionário pós-tarefas: Buscou medir as métricas ligadas a meta de satisfação - de M6 até M15. O questionário QUIS (SHNEIDERMAN, et al. 2016), por ser reconhecidamente validado e permitir flexibilidade no seu uso e análise, foi utilizado para gerar uma versão adaptada. Devido às alterações, foi realizada a verificação da consistência interna do questionário por meio do Alpha, definindo-se que seriam feitas intervenções nos itens com resultados com $\square<0,7$. Apenas a questão 2 do item "Esforço" foi retirada para melhorar a consistência, resultando em todos os itens com Alpha próximo de 0.9, confirmando estatisticamente a confiabilidade do questionário, conforme tabela 2. 
Tabela 2: Resultados para Alpha.

$\begin{array}{llll}\text { Alpha fi- } & \text { P.1 } & \text { P.2 } & \text { P.3 }\end{array}$

nal

\begin{tabular}{lccll}
\hline Tela & 0,76 & 0,92 & 0,67 & 0,43 \\
\hline Utilidade & 0,89 & 0,96 & 0,79 & 0,78 \\
\hline Terminologia & 0,7 & 0,87 & 0,70 & 0,49 \\
\hline Atratividade & 0,83 & 0,84 & 0,85 & 0,57 \\
\hline Aprendizagem & 0,87 & 0,66 & 0,91 & 0,79 \\
\hline $\begin{array}{l}\text { Capacidade do sis- } \\
\text { tema }\end{array}$ & 0,9 & 0,90 & 0,86 & 0,79 \\
\hline
\end{tabular}

\begin{tabular}{lllll}
\hline Uso futuro & 0,92 & 0,86 & 0,86 & - \\
\hline $\begin{array}{l}\text { Expectativa antes } \\
\text { uso }\end{array}$ & 0,78 & 0,74 & 0,74 & - \\
\hline
\end{tabular}

\begin{tabular}{lcccc}
\hline $\begin{array}{l}\text { Expectativa pós } \\
\text { uso }\end{array}$ & 0,78 & 0,68 & 0,68 & - \\
\hline Esforço & 0,86 & 0,76 & 0,55 (retirada) & 0,76 \\
\hline Satisfação geral & 0,95 & $\begin{array}{c}0,96 \\
\text { Fonte: Software Stata v. 15. }\end{array}$ & 0,92
\end{tabular}

(4) Entrevista do tipo debriefing: Entrevista semiestruturada com o usuário pós-teste, objetivando revisar e coletar mais informações sobre a percepção do usuário, reforçando também os dados da métrica M6.

\subsection{Identificar as questões práticas}

Definiu-se que a amostra do estudo seria selecionada por julgamento, sendo que vinte leitores exclusivamente de revista impressa (critério de inclusão ser assinantes ou consumidor de exemplares avulsos e não ter tido contato com revista digital) formaram dois grupos não pareados e estratificados entre 20-44 e 45-64 anos, faixas etárias que representam 71\% dos leitores de revistas no Brasil (GRUPO DE MÍDIA SÃO PAULO, 2017). Embora não fosse o objetivo principal, buscou-se dessa forma também averiguar diferenças na percepção de uso de acordo com a faixa etária. Devido às restrições de tempo, custos e cronograma, todos os testes foram realizados em Florianópolis/SC.

A coleta de dados ocorreu em ambiente natural escolhido pelos leitores, utilizando um laptop do pesquisador. A posição dos participantes e do moderador foi padronizada para captura dos dados, sendo realizada a filmagem dos testes utilizando um smartphone com tripé que era focado na tela do computador.

Como última etapa dessa fase, foi realizado um pré-teste com dois usuários para a validação da dinâmica dos procedimentos do teste e das ferramentas que seriam utilizadas, sendo procedidos alguns ajustes na definição das tarefas e na redação dos questionários. Logo após três usuários de 20-44 anos e três de 45-64 já utilizadores da banca realizaram as tarefas propostas para coleta da performance ideal (tempo de benchmark). 


\subsection{Decidir como lidar com questões éticas}

O projeto foi submetido ao Comitê de Ética em Pesquisas Envolvendo Seres Humanos da Universidade do Estado de Santa Catarina recebendo parecer positivo (Parecer $n^{\circ}$ 2.710.716). Para participação no estudo os usuários deveriam assinar o Termo de Consentimento Livre e Esclarecido, que especificava as condições acordadas.

\subsection{Definições sobre avaliação, interpretação e apresentação dos dados}

Definiu-se que o plano de tratamento de dados começaria pela revisão dupla dos vídeos das sessões, sendo a primeira revisão realizada para capturar os dados relacionados às métricas de desempenho e a segunda para analisar os comentários realizados durante o teste e na sessão de debriefing, passando-se para a tabulação dos dados obtidos por meio dos questionários.

Os dados colhidos para cada uma das quinze métricas foram analisados separadamente utilizando-se escalas com resultado binário, sendo as métricas classificadas com um "impacto positivo" ou "impacto negativo" parcial sobre a percepção de usabilidade.

Para as métricas de desempenho (quantitativas) a escala foi definida em um intervalo $0-100 \%$ (notas $<60 \%=$ impacto negativo na percepção de usabilidade sendo 0-30\% (Péssimo); 31-60\% (Ruim); 61-80\% (Bom) e 81-100\% (Ótimo).

No caso das métricas colhidas por questionário, utilizou-se frequências tabuladas e o resultado final parcial realizado por meio da média das respostas da escala Likert de 9 pontos. A escala de avaliação foi baseada em intervalos de aceitabilidade sendo a nota 1 como limite inferior negativo e a nota 9 como o limite superior positivo de avaliação para cada item. $O$ resultado do critério foi avaliado de acordo com a categorização das notas, onde 1-3 (impacto péssimo), 4-5 (impacto ruim), 6-7 (impacto bom) e 8-9 (impacto ótimo).

A partir da tabulação dos resultados coletados, utilizou-se primeiramente estatística descritiva, e no caso dos dados quantitativos verificou-se a normalidade dos dados (teste Shapiro - Wilk), definindo-se assim testes estatísticos adequados à análise de cada métrica, realizados posteriormente no software Stata v.15.

Como última etapa de tratamento de dados e de forma de responder ao questionamento central da pesquisa, procedeu-se uma regressão logística demonstrando como cada um dos critérios analisados impactaram a percepção positiva de uso da banca (representado pelo critério usabilidade geral).

\section{RESULTADOS E DISCUSSÃO}

A totalidade da amostra possuía ao menos ensino superior incompleto com grande variação nas ocupações. Quanto ao gênero, $70 \%$ eram do sexo feminino e $30 \%$ do sexo masculino. Todos os participantes tinham mais de dois anos de experiência com informática, $85 \%$ deles permanecem mais de 4 horas/dia conectados à internet. Todos também foram assinantes de revistas, sendo a compra avulsa o meio mais utilizado para adquiri-las atualmente. A frequência de leitura de revistas é de uma ou duas vezes por semana (90\%). A maioria (95\%) indicou já ter conhecimento da existência das 
versões digitais de revistas e 30\% apontaram conhecimento de bancas digitais. Abaixo são apresentados os resultados e análises unitárias de cada métrica e seus impactos na percepção de uso da banca digital.

\subsection{Sucesso na Tarefa}

Mediu se o usuário conseguia ou não alcançar seus objetivos (completar as tarefas), podendo apontar para problemas estruturais na interface ou arquitetura de informação.

O grupo 1 (20-44 anos) realizou 98\% das tarefas propostas, o grupo 2 (45-64 anos) 92\% e no geral a taxa de conclusão foi de 95\%. Os testes Chi-Quadrado e teste Exato de Fisher, cálculos estatísticos voltados para aferição executados para cada para cada tarefa, não mostraram diferenças significativas entre os grupos ( $p>0.5)$. A tarefa 1 foi problemática, indicando um caso isolado e impactando mais o grupo 2 que teve $60 \%$ de sucesso nessa tarefa. Duas questões são importantes nesta análise: a tarefa 1 foi o primeiro ponto de contato com o produto, portanto podia-se esperar algum tipo de influência no resultado. A segunda questão verificada nos testes é que havia um problema relacionado à utilização do recurso "favoritar" - um dos focos da tarefa, e a dificuldade de identificação do botão na interface levou muitos usuários a abandoná-la após diversas tentativas.

Levando-se em conta o resultado geral, chega-se a uma porcentagem de sucesso geral de $95 \%$, sendo a métrica classificada com impacto parcial positivo ótimo na percepção de usabilidade, conforme figura 4.

Figura 4: Resultado da métrica e impacto parcial sobre a percepção de usabilidade.

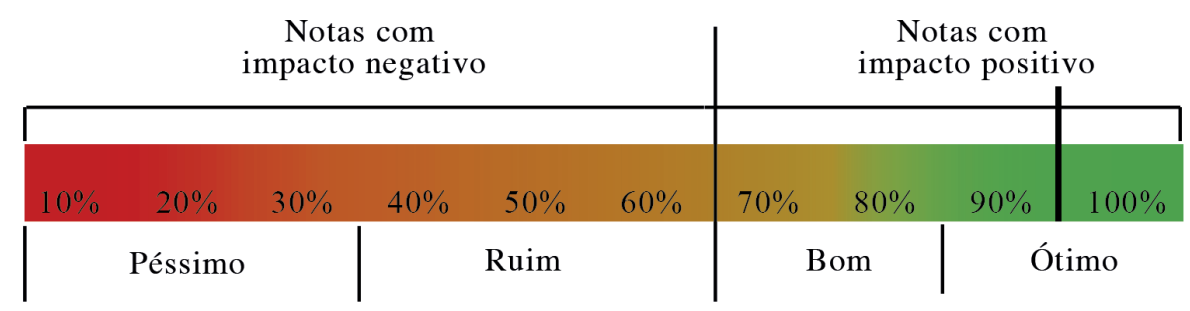

Fonte: Autor.

Considerando que as tarefas foram representativas de um uso típico, pode-se dizer que por esse prisma o produto possibilitou que um novo usuário fosse capaz de iniciar e finalizar ações suficientes para utilizar as funções principais da banca como encontrar, navegar e ler uma revista.

\subsection{Nível de sucesso na tarefa}

Mediu a qualidade na realização das tarefas (com ou sem erros), ajudando a entender a qualidade de uso do produto relacionado à eficácia de uso.

O grupo 1 realizou 78\% das tarefas sem erros e o grupo 2 72\%, sendo $75 \%$ o nível geral de sucesso na tarefa. Apenas na tarefa 1 demonstrou-se diferença significativa entre os grupos (Chi-quadrado =0,0062 / Fisher $=0.0198$ ). As tarefas 1 e 2 foram as que 
tiveram o menor nível de sucesso, provavelmente pela tarefa 1 proporcionar o primeiro contato do usuário com o sistema e pela dificuldade no uso das funções de buscar e favoritar. A tarefa 2 carecia da eficiência das funcionalidades de busca do sistema, não afetando tanto os grupos. As demais tarefas sucessivas apresentaram um alto nível de sucesso nos dois grupos, mostrando uma rápida curva de evolução de aprendizado, ou seja, apesar dos erros o sistema permitiu uma rápida apropriação de seu uso.

A porcentagem geral da métrica foi de $75 \%$, um impacto parcial positivo bom na percepção de usabilidade, conforme figura 5 .

Figura 5: Resultado da métrica e impacto parcial sobre a percepção de usabilidade.

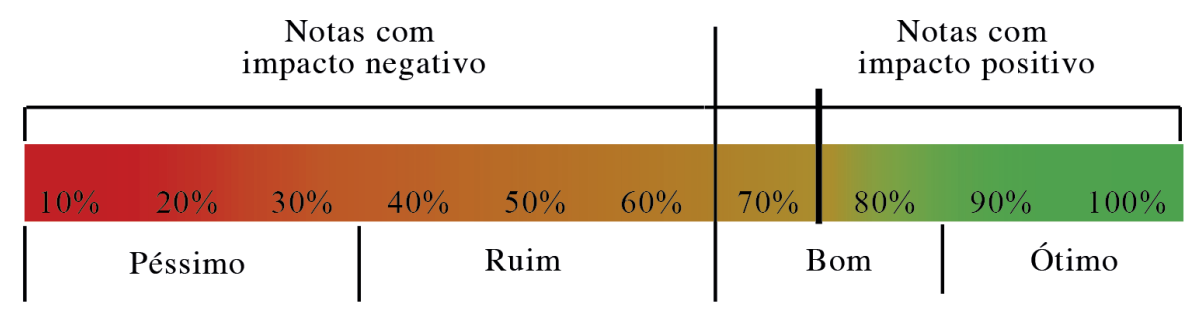

Fonte: Autor.

Cabe destacar o relato dos usuários durante os testes sobre a necessidade de meIhorar a interação em alguns pontos específicos (que afetaram as tarefas 1 e 2). Comparando os resultados da métrica Sucesso na Tarefa e Nível de Sucesso na tarefa, é possível verificar que embora existam problemas que dificultam seu uso, a banca de modo geral oferece uma boa eficácia.

\subsection{Eficiência relativa}

Comparou o tempo de um usuário novato e o tempo de um usuário especialista (tempo benchmark/ideal) para se executar a mesma tarefa nas mesmas condições, e teve como objetivo verificar possíveis barreiras na utilização do produto que aumentassem o tempo e esforço cognitivo para que as tarefas fossem executadas.

Alguns eventos ocorridos durante os testes foram desconsiderados na contagem de tempo da métrica, como falhas na abertura das revistas, travamentos do sistema, períodos onde o usuário executava ações que não contribuíam direta ou indiretamente para finalização da ação, além de pausas para relatos. A média de tempo total para realizar as 5 tarefas no grupo 1 foi de 206,5s, no grupo 2 de 413,5s e a média geral de 329s. O tempo benchmark (usado como tempo ideal de comparação) na faixa de 2044 anos foi de $87 \mathrm{~s}$, na faixa de $45-64$ anos foi de 119s. A partir da não normalidade dos dados utilizou-se o Teste de Kruskall-Wallis para comparar o desempenho dos grupos em cada tarefa, não se apontando diferenças estatísticas significativas.

Aplicando-se uma equação de grandeza inversamente proporcional (quanto mais tempo, menor a eficiência) considerando o tempo benchmark como padrão de $100 \%$ de eficiência (para o grupo 187s e para o grupo 2119s) e o tempo dos usuários (206,5 no grupo 1 e 413s no grupo 2), verificou-se que a eficiência geral dos usuários nos dois grupos foi próxima de $31 \%$, tendo um impacto parcial ruim na percepção de usabilidade, conforme figura 6. 
Figura 6: Resultado da métrica e impacto parcial sobre a percepção de usabilidade.

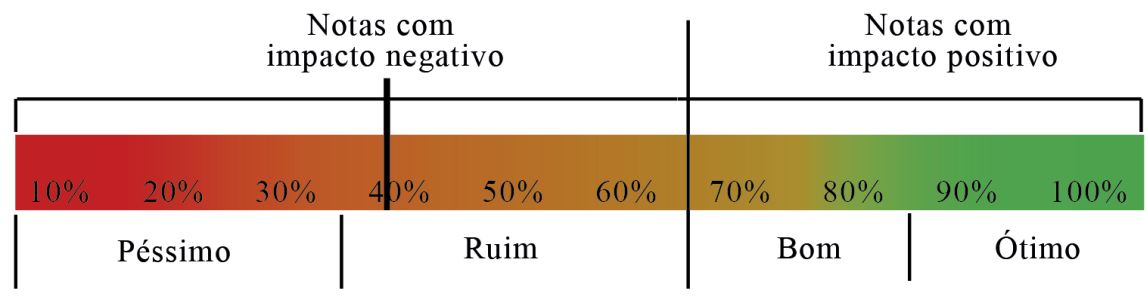

Fonte: Autor.

Embora o usuário tenha conseguido realizar a maioria das tarefas (sucesso na tarefa) relativamente com poucos erros (nível de sucesso na tarefa), levou-se muito tempo para a execução das mesmas, afetando negativamente a experiência de uso do formato digital.

\subsection{Nível de eficiência}

A métrica relacionou os níveis de eficácia atingidos em relação ao tempo gasto na execução da tarefa, mostrando quantas tarefas os usuários conseguiram finalizar no tempo ideal (de benchmark), mostrando a eficiência do uso do produto de forma geral.

A média de tempo benchmark (nos grupo 1 e 2) para realizar as 5 tarefas foi de 104s, sendo assim 21s por tarefa (104s / 5 tarefas). Já a média geral de tempo dos usuários (grupo 1 e 2) para realizar as 5 tarefas (excluindo-se o tempo de 4 usuários que não executaram todas as tarefas) foi de $232 \mathrm{~s}$, levando a um tempo de $46 \mathrm{~s}$ por tarefa (232s / 5 tarefas).

Considerando o tempo total ideal para realizar as 5 tarefas (benchmark - 104s) e o tempo utilizado pelos usuários para realizar cada tarefa $(46,4 \mathrm{~s})$, no tempo ideal seria possível realizar apenas 2 tarefas completas das 5 propostas, o que corresponde a um nível de eficiência de $40 \%$. Assim a métrica classificou-se com um impacto parcial negativo ruim sobre a usabilidade, conforme figura 7.

Figura 7: Resultado da métrica e impacto parcial sobre a percepção de usabilidade.

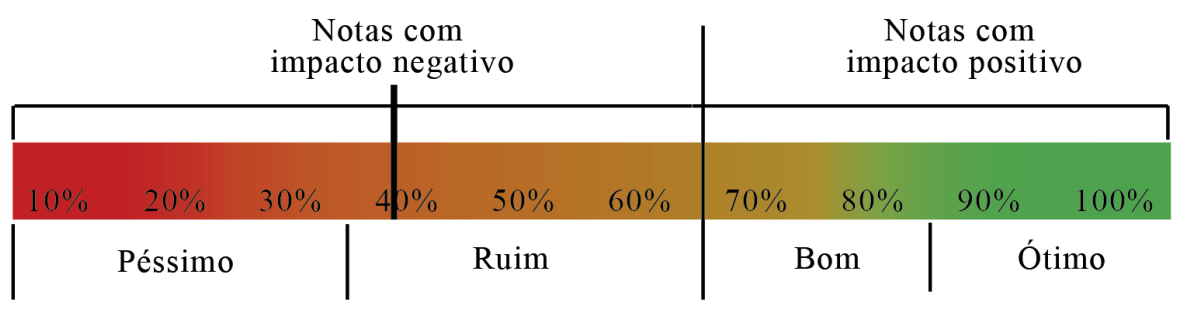

Fonte: Autor.

Os usuários que tiveram desempenho pior expressaram frustração, comparando o uso do digital com a facilidade do manuseio da versão impressa. 


\subsection{Aprendizagem}

A métrica foi autorrelatada pelos usuários (questionário) e indicou a capacidade de aprendizado e memorização ao (re) utilizar o sistema.

O grupo 1 atribuiu nota média de 6,7, o grupo 2 nota 7,7 e a nota média final foi 7,2. O teste de Wilcoxon-Mann-Whitney (dados não paramétricos, para $p=0.05$ ) não mostrou diferenças significativas de opinião entre os grupos $(p=0.06)$, observada também nas frequências das notas atribuídas para o fator. Pelo cruzamento dos resultados verificou-se que embora alguns resultados ligados à meta de performance sejam negativos, os usuários consideraram que mesmo assim o sistema proporcionou uma boa possibilidade de aprendizagem e facilidade de uso.

Com média final de 7,2 o critério foi bem avaliado de forma geral, com um impacto parcial positivo bom sobre a usabilidade, conforme figura 8.

Figura 8: Resultado da métrica e impacto parcial sobre a percepção de usabilidade.

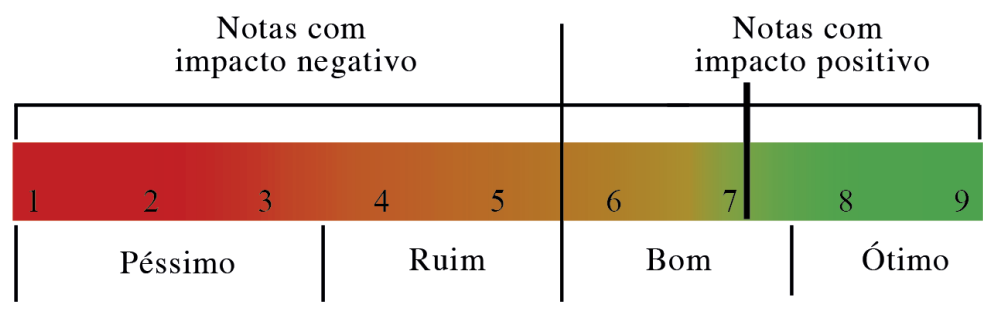

Fonte: Autor.

Os usuários, inclusive aqueles que tiveram maiores problemas de desempenho, consideraram que o sistema proporcionou uma boa possibilidade de aprendizagem e facilidade de uso, o que levaria rapidamente a uma melhora da performance.

\subsection{Comentários}

A métrica de cunho qualitativo (descritivo) e quantitativo (frequência) ajudou a demonstrar o grau de qualidade sobre o produto a partir da opinião direta sobre pontos específicos, sendo os comentários negativos ligados diretamente aos problemas de usabilidade identificados pelos usuários.

Dos 129 comentários, $74 \%$ foram negativos e $26 \%$ positivos. Partindo-se do total de comentários negativos, verifica-se que o grupo 1 foi mais crítico (57 comentários negativos - 59\%), sendo que do total de comentários no grupo $78 \%$ foram negativos e $22 \%$ positivos. No grupo 2 foram 70 comentários realizados, sendo $73 \%$ negativos e $27 \%$ positivos. Assim, embora os comentários ao produto tenham sido mais negativos que positivos, o grupo 2 apresentou resultados sensivelmente melhores. Considerando a frequência das reclamações e classificando-as de acordo com o grau de severidade, foram 34 ocorrências de grau 1 (menor); 45 de grau 2 (médio) e 17 de grau 3 (grave). Reclamações relacionadas ao fator Tela, Capacidade do sistema e Utilidade representaram a maioria das ocorrências.

Considerando que a porcentagem de comentários positivos foi de $26 \%$ do total 
de comentários, avalia-se que a métrica tem um impacto parcial negativo péssimo sobre a percepção da usabilidade, ou seja, parte dos usuários teve uma impressão mais negativa nesse ponto, conforme figura 9.

Figura 9: Resultado da métrica e impacto parcial sobre a percepção de usabilidade.

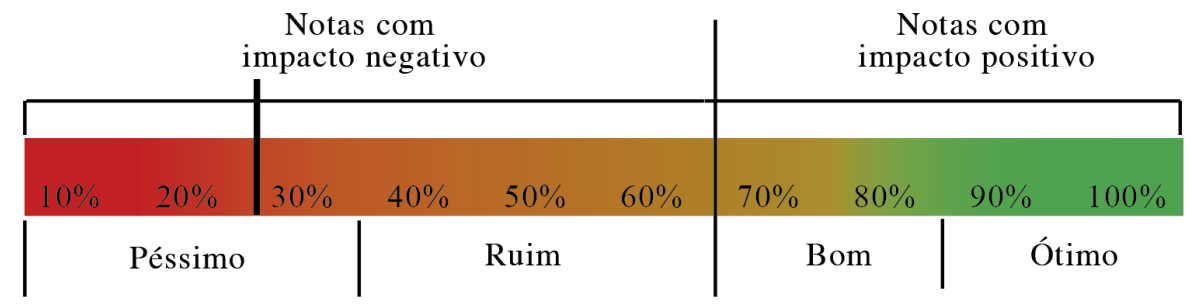

Fonte: Autor.

\subsection{Expectativa antes e após uso}

Foi uma métrica psicométrica autorrelatada através da aplicação das mesmas questões de diferencial semântico antes e após o uso do produto, e ajudou a entender se a expectativa do usuário em relação ao produto foi alcançada.

O grupo 1 atribuiu nota média 5,8 antes do uso (após o uso nota 4), o grupo 2 a nota média antes do uso foi 8,3 (após o uso nota 8,4 ). No geral a nota média antes do uso foi 7 e após o uso 6,4. O teste Wilcoxon-Mann-Whitney (dados não paramétricos, $\mathrm{p}=0.05)$ mostrou que os grupos tiveram opiniões estatisticamente diferentes da expectativa antes $(p=0.001)$ e depois $(p=0.001)$. Analisando as frequências e médias, a expectativa no grupo 1 já era baixa e diminuiu mais após o uso, já no grupo 2 a expectativa antes do uso era alta e teve um aumento, ou seja, o grupo 2 achou o produto muito mais fácil e interessante de usar ao final do teste que o grupo 1. Comparando a média final dos dados colhidos para a expectativa entre os dois grupos antes e após uso, verificou-se que os usuários fizeram uma avaliação mais negativa após o uso, mas de forma geral a métrica é classificada com um impacto parcial positivo bom sobre a percepção da usabilidade, conforme figura 10.

Figura 10: Resultado da métrica e impacto parcial sobre a percepção de usabilidade.

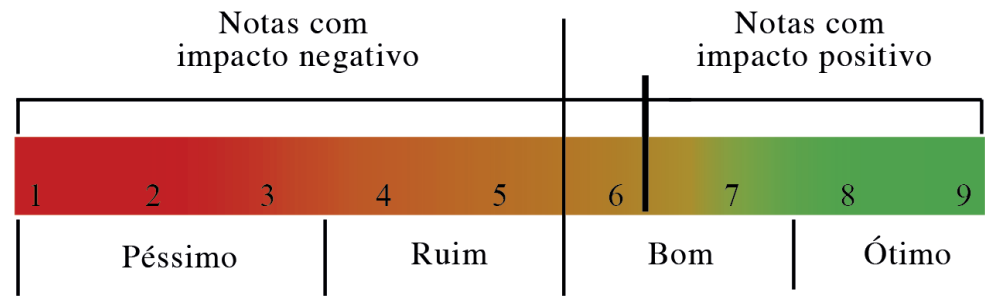

Fonte: Autor.

Considera-se que a expectativa de uso positiva é um fator importante para adoção do produto banca digital cuja futura e contínua adoção depende principalmente da faixa etária mais jovem, e que mostrou pouca recepção tanto antes como após testar o produto. 


\section{$5.8 \quad$ Utilidade}

A métrica foi autorrelatada pelos usuários (questionário), medindo se o sistema fornecia ao usuário um conjunto de funções esperadas no contexto de uso, de forma a ajudar, facilitar e permitir o atingimento das metas para que as tarefas fossem concluídas.

O grupo 1 atribuiu nota média 5,3, o grupo 2 nota 7,1 e a nota média geral foi 6,2. O teste de Wilcoxon-Mann-Whitney (dados não paramétricos, para $p=0.05$ ) mostrou que os grupos tiveram opiniões estatisticamente diferentes sobre a utilidade $(p=0.00)$. Analisando a frequência das notas e a média verificou-se que o grupo 1 foi mais crítico, possivelmente pelo maior contato e repertório com outros sistemas digitais voltados para consumo de informação. A falta de funções disponíveis (zoom, falta de ferramentas mais efetivas para navegação dentro da revista) impactou negativamente o fator.

A nota média final do critério foi de 6,2, classificando-se com um impacto parcial positivo bom sobre a usabilidade, mas no limite da aceitabilidade, levando-se em conta também os comentários negativos apontados sobre tal ponto, conforme figura 11

Figura 11: Resultado da métrica e impacto parcial sobre a percepção de usabilidade.

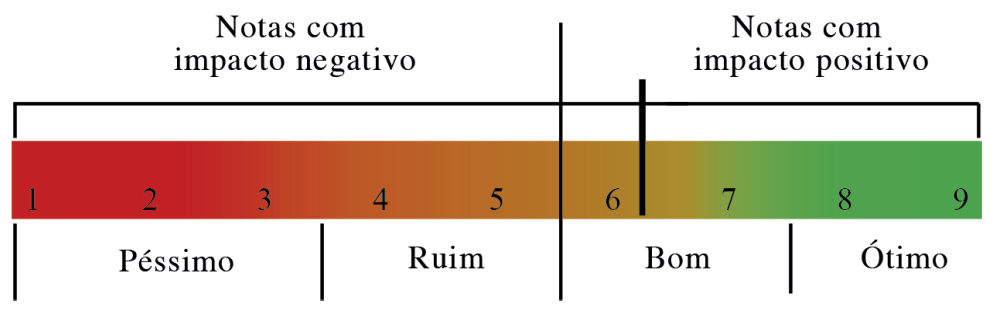

Fonte: Autor.

Percebeu-se pela análise geral que embora fosse possível realizar todas as tarefas com os recursos disponíveis, considerando que a banca é um sistema voltado para o entretenimento onde o usuário tem a opção de usá-lo ou não, é necessário prover meIhores recursos para exploração da plataforma digital, a ponto de compensar o uso da revista impressa.

\subsection{Atratividade}

A métrica foi autorrelatada pelos usuários (questionário) e mediu a experiência de uso buscando avaliar o quanto o usuário sentiu-se atraído pelo produto levando em consideração as questões hedônicas.

O grupo 1 atribuiu nota média 6,4, ○ grupo 2 nota 8 e a nota média geral foi 7,2. 0 teste de Wilcoxon-Mann-Whitney (dados não paramétricos, para $p=0.05$ ) mostrou que os grupos tiveram opiniões estatisticamente diferentes sobre a atratividade da banca $(p=0.04)$. Analisando a frequência das notas e a média verifica-se que o grupo 1 achou o produto menos atrativo que o grupo 2 .

Considerando a nota média final do critério $(7,2)$, classificou-se com um impacto parcial positivo ótimo sobre a usabilidade, conforme figura 12. 
Figura 12: Resultado da métrica e impacto parcial sobre a percepção de usabilidade.

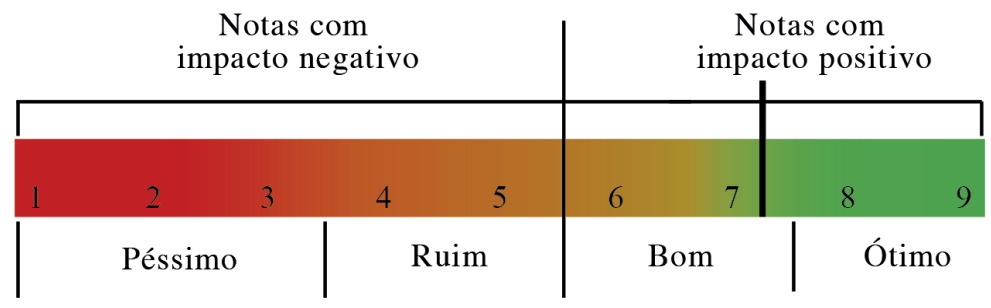

Fonte: Autor.

O resultado derivado da atratividade é um fator importante no caso da banca digital, pois as características emocionais têm um peso grande na adoção de produtos, podendo ser considerado um dos fatores motivantes para um primeiro uso. $O$ resultado mostrou que o grupo mais jovem achou o produto menos atrativo.

\subsection{Uso futuro}

A métrica foi autorrelatada pelos usuários (questionário) e verificou como o usuário avaliava a possibilidade hipotética de adotar o produto.

O grupo 1 atribuiu nota média 5,8, o grupo 2 nota 7,5 e a nota média geral foi 6,7. O teste de Wilcoxon-Mann-Whitney (dados não paramétricos, para $p=0.05$ ) mostrou que os grupos tiveram opiniões estatisticamente parecidas ( $p=0.08$ ), embora a análise das frequências das notas e observação durante os testes mostrou que o grupo 1 teria menor tendência a uma possível adoção da banca. A falta de funções essenciais, questões relacionadas à capacidade do sistema e preferência ao analógico foram as justificativas no caso de respostas negativas ao item.

Considerando a média final do critério $(6,7)$, classificou-se com um impacto parcial positivo bom sobre a usabilidade, conforme figura 13.

Figura 13: Resultado da métrica e impacto parcial sobre a percepção de usabilidade.

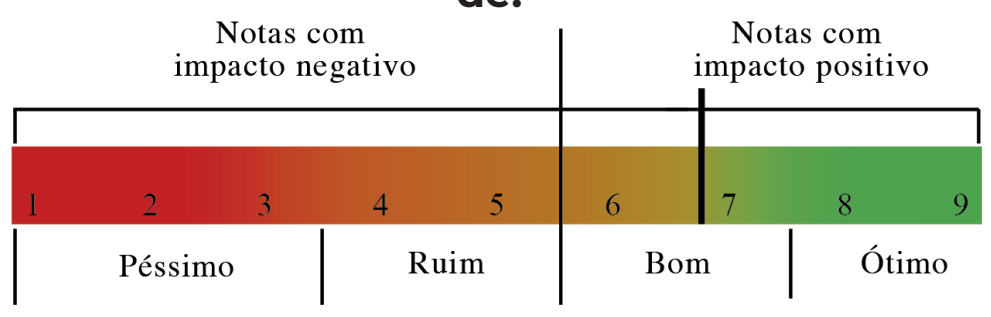

Fonte: Autor.

O resultado mostrou que embora se verifique uma possibilidade de futura adoção da banca pelos usuários, é necessário oferecer um sistema mais equilibrado corrigindo falhas e falta de recursos, principalmente para atrair o público de faixa etária mais jovem que espera um sistema que aproveite melhor os recursos da plataforma digital. 


\subsection{Esforço de utilização}

A métrica foi autorrelatada pelos usuários (questionário) e mediu a satisfação do usuário com o esforço físico (necessidade do uso do mouse ou teclado, esforço visual) e mental (necessidade de concentração) para utilizar o produto, considerando tarefas típicas.

O grupo 1 atribuiu nota média 6,7, o grupo 2 nota 7,5 e a nota média geral foi 7. 0 teste de Wilcoxon-Mann-Whitney (dados não paramétricos, para $p=0.05$ ) mostrou que os grupos tiveram opiniões estatisticamente parecidas $(p=0.21)$, embora considerando a análise das frequências das notas e observação durante os testes que o grupo 2 avaliou o esforço de forma mais positiva.

Considerando a média final do critério (7), classificou-se com um impacto parcial positivo bom sobre a usabilidade, conforme figura 14.

Figura 14: Resultado da métrica e impacto parcial sobre a percepção de usabilidade.

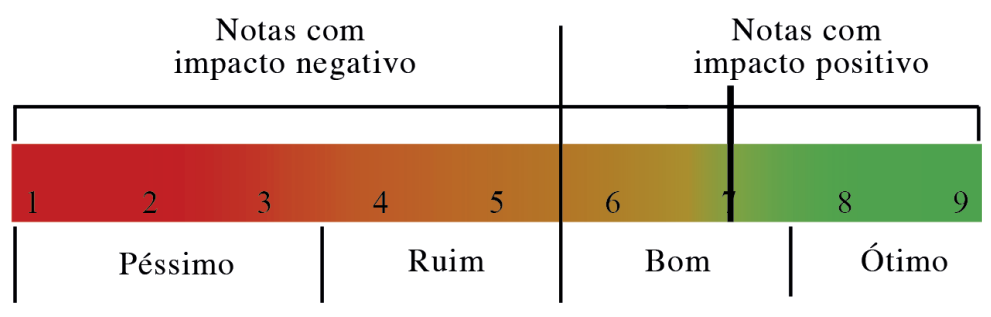

Fonte: Autor.

Tal resultado é um ponto importante por equalizar no plano perceptivo o uso do sistema digital frente ao físico. Caso o esforço fosse considerado um ponto negativo, seria uma barreira de uso para a mudança de suporte.

\subsection{Tela}

A métrica foi autorrelatada pelos usuários (questionário) e mediu a satisfação do usuário com a qualidade, organização e design da interface geral da banca.

O grupo 1 atribuiu nota média 5,9, o grupo 2 nota 6,9 e a nota média geral foi 6,3. O teste de Wilcoxon-Mann-Whitney (dados não paramétricos, para $p=0.05$ ) mostrou que os grupos tiveram opiniões estatisticamente parecidas $(p=0.20)$, embora considerando as frequências e observação durante os testes, o grupo 1 apontou mais a falta de recursos relacionados à tela. A organização da informação foi o item que gerou mais críticas, pois esperava-se que a tela principal da banca tivesse uma relação / simulação mais próxima da banca física (metáfora visual), com a apresentação das capas dos títulos logo na entrada.

Considerando a nota média final do critério $(6,3)$, classificou-se com um impacto parcial positivo bom sobre a usabilidade, conforme figura 15. 
Figura 15: Resultado da métrica e impacto parcial sobre a percepção de usabilida-

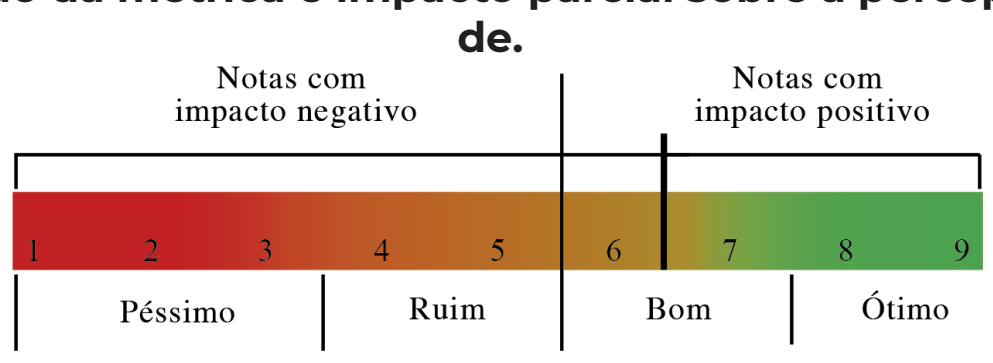

Fonte: Autor.

A tela é um fator significativo para o sucesso do produto, pois de forma geral é o contato visual com ela que causa as primeiras percepções gerais sobre o sistema. Além disso, a leitura da revista em tela não foi vista como um ponto negativo mesmo para os usuários que relataram apego ao modelo impresso, sendo essa questão um resultado positivo para a aceitabilidade da banca digital.

\subsection{Terminologia e informação do sistema}

A métrica foi autorrelatada pelos usuários (questionário) e mediu a satisfação do usuário com a terminologia geral utilizada no sistema para nomear menus, seções, funções, dar mensagens, além da posição de tais recursos na interface.

O grupo 1 atribuiu nota média 5,9, o grupo 2 nota 7 e a nota média geral foi 6,7 . 0 teste de Wilcoxon-Mann-Whitney (dados não paramétricos, para $p=0.05$ ) mostrou que os grupos tiveram opiniões estatisticamente parecidas $(p=0.96)$.

Considerando a nota média final do critério $(6,7)$, classificou-se com um impacto parcial positivo bom sobre a usabilidade, conforme figura 16.

Figura 16: Resultado da métrica e impacto parcial sobre a percepção de usabilidade.

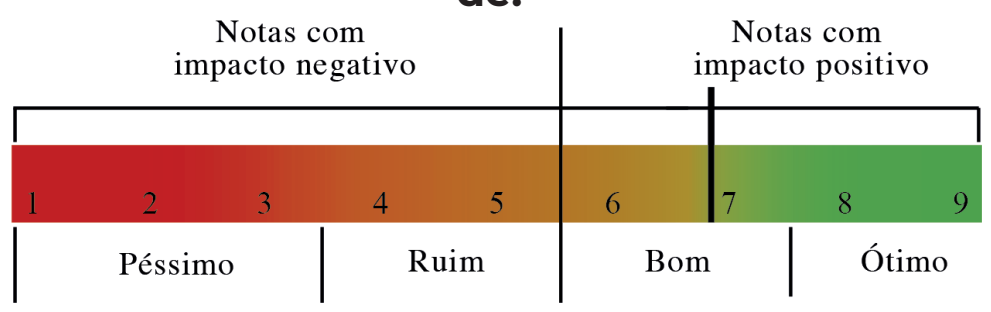

Fonte: Autor.

Avaliou-se que o uso de termos na banca de forma geral é simples e com nomenclaturas claras, graças à pouca profundidade de navegação que leva à adoção de menus e sub menus bem definidos em sua função.

\subsection{Capacidade do sistema}

A métrica foi autorrelatada pelos usuários (questionário) medindo a satisfação do usuário com a velocidade do sistema (o quão rápido ele reagia às ações do usuário além do tempo para carregamento das páginas), os caminhos que o sistema fornecia 
para a recuperação de erros durante a execução de tarefas, além de avaliar se o sistema foi projetado para todo tipo de usuário, ou seja, se qualquer usuário, em qualquer condição específica teria facilidade de usá-lo).

O grupo 1 atribuiu nota média 4,9, o grupo 2 nota 6,2 e a nota média geral foi 5,7. O teste Wilcoxon-Mann-Whitney (dados não paramétricos, para $p=0.05$ ) mostrou que os grupos tiveram opiniões estatisticamente parecidas $(p=0.45)$. A velocidade de carregamento das páginas da revista foi considerada crítica pelos usuários.

Considerando a nota média final do critério $(5,7)$, classificou-se com um impacto parcial negativo ruim sobre a percepção da usabilidade, conforme figura 17.

Figura 17: Resultado da métrica e impacto parcial sobre a percepção de usabilidade.

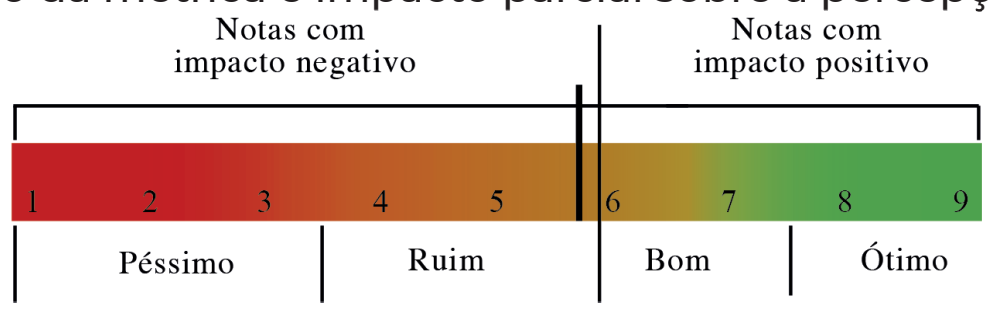

Fonte: Autor.

Avaliou-se de forma geral que o sistema não foi projetado para todos os níveis de usuário, considerando que não seria facilmente usado por pessoas sem um maior conhecimento de recursos de informática e nem por usuários com problemas de visão (devido à falta de recursos para adaptar a tela para atender tal necessidade). A capacidade do sistema é um item importante para o usuário, pois diz respeito a questões das quais ele não tem controle, portanto a banca deixa a desejar nesse sentido por não oferecer um controle mais próximo do oferecido pelo produto físico.

\subsection{Satisfação geral de uso}

A métrica foi autorrelatada pelos usuários (questionário) e mediu as reações gerais e finais do usuário sobre o produto através da sua percepção de satisfação.

O grupo 1 atribuiu nota média 5,5, o grupo 2 nota 7,3 e a nota média geral foi 6,4. O teste Wilcoxon-Mann-Whitney (dados não paramétricos, para $p=0.05$ ) mostrou que os grupos tiveram opiniões estatisticamente diferentes $(p=0.02)$. Considerando a frequência de notas atribuídas e a média das respostas, o grupo 1 está mostrou-se mais insatisfeito com o sistema, o que espelha os resultados das demais análises anteriores.

Considerando a nota média final do critério $(6,4)$, classificou-se com um impacto parcial positivo bom sobre a usabilidade, conforme figura 18. 
Figura 18: Resultado da métrica e impacto parcial sobre a percepção de usabilidade.

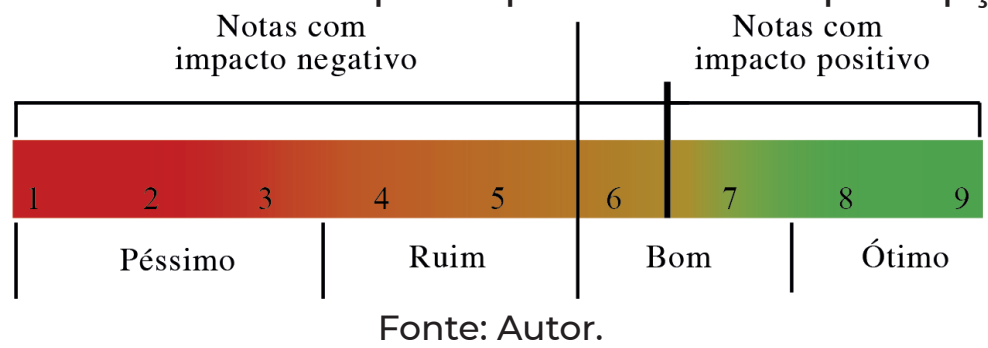

Embora avaliou-se o critério positivamente, deve-se levar em conta a relevância da percepção do grupo 1, sendo que tal resultado espelha a avaliação das demais métricas avaliadas. Isso mostra que o produto precisa adequar-se em diversos pontos para que possa atrair principalmente o público mais jovem.

\section{AVALIAÇÃO DOS RESULTADOS SOBRE O PRISMA DA USABILIDADE}

Como análise final, os resultados individuais de cada métrica foram relacionados com seus impactos na experiência do usuário por meio da aplicação de um cálculo estatístico de regressão logística (com $p=0.02$ ). Buscou responder ao seguinte questionamento: "Qual (ou quais) a(s) variável(eis) exploratória(s) são preditivas/ explicadoras da percepção positiva de uso da banca digital?", possibilitando verificar como as variáveis independentes (as métricas analisadas) influenciam a ocorrência da variável dependente (percepção positiva de uso - sintetizada pela variável "Satisfação geral"). Para que o método pudesse ser aplicado utilizando as diferentes variáveis estudadas foi necessário que seus valores fossem codificados em escala binária, sendo 0 definido como não ocorrência do fenômeno (não contribui para a variável dependente ocorrer) e 1 como ocorrência do fenômeno (contribui para a variável dependente ocorrer), criando-se algumas regras para a conversão dos resultados para cada métrica. O processo foi realizado por meio do sistema backward, que parte de um modelo inicial com todas as variáveis independentes que vão sendo excluídas caso apresentem pouca significância na variável resposta (de acordo com o p valor adotado).

Como resultado as variáveis "Nível de eficiência" e "Comentários" foram descartadas por apresentarem baixa colinearidade. Entende-se que a variável Nível de eficiência pode ser representada pela variável Eficiência relativa (que entrou no modelo) sendo assim contemplada na avaliação. Já a variável Comentários foi analisada sob o prisma qualitativo.

As variáveis Sucesso na tarefa $(p=0,726)$, Nível de sucesso na tarefa $(p=0,600)$ e Eficiência relativa ( $\rho=726)$ mostraram não ter influência na percepção positiva de uso $(p \geq 0,2)$. Isso mostra que embora a maioria das métricas de desempenho resultou em impacto parcial negativo, não tiveram grande impacto na percepção de uso, possivelmente devido ao objetivo do sistema ser de entretenimento. Tal posicionamento foi também demonstrado verbalmente pelos usuários que expressavam frustração momentânea com seu desempenho na realização das tarefas, mas avaliavam que com o uso continuo a eficácia e eficiência seriam melhores.

Como resultado final, Tela $(p=0,015)$, Esforço $(p=0,008)$ e Terminologia $(p=0,019)$ somadas impactaram em aproximadamente $52 \%$ a percepção positiva de uso da ban- 
ca (soma dos valores pseudo R2 das três variáveis). A tabela 1 apresenta os resultados considerando as relações entre o impacto parcial e final obtido por meio da regressão logística.

Quadro 1 - Impacto final das métricas sobre a percepção positiva de uso.

\begin{tabular}{|c|c|c|c|c|}
\hline Meta & Métrica & \multicolumn{2}{|c|}{ Impacto Parcial } & Impacto final \\
\hline & & Negativoo & Positivo & \\
\hline \multirow{5}{*}{$\begin{array}{l}\text { Meta } \\
\text { Desempenho }\end{array}$} & M.1 Sucesso na tarefa & & $\mathrm{x}$ & Nenhum \\
\hline & $\begin{array}{l}\text { M.2 Nível de Sucesso na } \\
\text { tarefa }\end{array}$ & $\mathrm{x}$ & & Nenhum \\
\hline & M.3 Eficiência relativa & $x$ & & Nenhum \\
\hline & M.4 Nível de Eficiência* & $x$ & & - \\
\hline & M.5 Aprendizagem & & $x$ & Baixo \\
\hline \multirow{10}{*}{$\begin{array}{l}\text { Meta } \\
\text { Satisfação }\end{array}$} & M.6 Comentários* & $x$ & & - \\
\hline & M.7 Expectativa de uso & & $\mathrm{X}$ & Baixo \\
\hline & M.8 Utilidade & & $\mathrm{x}$ & Baixo \\
\hline & M.9 Atratividade & & $\mathrm{x}$ & Baixo \\
\hline & M.10 Uso Futuro & & $x$ & Baixo \\
\hline & M.11 Esforço & & $x$ & Alto \\
\hline & M.12 Tela & & $\mathrm{x}$ & Alto \\
\hline & M.13 Terminologia & & $\mathrm{x}$ & Alto \\
\hline & $\begin{array}{l}\text { M.14 Capacidade do sis- } \\
\text { tema }\end{array}$ & $x$ & & Baixo \\
\hline & M.15 Satisfação Geral** & & $x$ & - \\
\hline
\end{tabular}

Fonte: Autor.

Tela é um fator relevante, pois indica que a digitalização da banca e da revista não é um fator impeditivo do uso da banca pelo leitor analógico, sendo que pode ser interpretado também como um fator que pode ter grande impacto na mudança cultural que pode levar a adoção da versão digital de revistas.

O impacto da variável Esforço de uso também é uma questão importante, pois se avalia que um dos principais pressupostos do produto - a comodidade de acesso aos títulos é apreciada e percebida pelo usuário.

Já a métrica Terminologia representa uma questão mais trivial de uso, já que a banca foi avaliada como suficientemente intuitiva pelos usuários de forma geral, ou seja, acabou tendo um maior impacto positivo por ser um recurso menos exigido para um uso agradável.

Considerando tal resultado (impacto efetivo de três critérios), conclui-se que as demais dimensões necessitam ser melhoradas contribuindo mais efetivamente para que a usabilidade seja percebida como um fator importante para a adoção da banca digital por leitores analógicos. 


\section{CONSIDERAÇÕES FINAIS}

O mercado editorial de revistas está em crise, verificando-se uma queda da circulação geral não compensada pelo advento do formato digital. Entretanto, o meio digital é crucial para sua sobrevivência. Como um produto relativamente novo, os sistemas de bancas digitais simbolizam uma nova era na distribuição e forma de acesso às revistas, onde a otimização das relações entre usabilidade e experiência do usuário são essenciais.

Nesse sentido os dados resultantes da meta de desempenho mostraram como itens positivos o Sucesso na tarefa, Nível de Sucesso na tarefa e Aprendizagem. Já os itens que colaboraram para uma percepção negativa da usabilidade foram Eficiência relativa e Nível de eficiência. No entanto, percebeu-se pela opinião dos usuários que o desempenho é relativizado, pois outras questões são consideradas mais importantes no uso de uma banca digital que é voltada para um momento de leitura e lazer. Isso foi confirmado por meio da regressão logística que mostrou que a maioria das métricas de desempenho tem baixa ou nenhuma influência na percepção positiva do uso do produto.

Em relação às metas de satisfação, classificaram-se como positivas em ordem crescente (pela média) os critérios Expectativa de uso; Utilidade; Tela; Uso futuro; Terminologia; Esforço e Atratividade. Classificados como negativos estão Comentários e Capacidade do sistema. De acordo com os resultados da regressão logística, os critérios Tela, Esforço e Terminologia contribuem aproximadamente com 52\% para a formação da percepção positiva de uso. Por outro lado, esse resultado pode ser interpretado como uma necessidade de revisão dos demais itens, que podem ser classificados com influência baixa ou negativa sobre a usabilidade (considerando os critérios com notas parciais negativas ou muito próximas do limite de aceitabilidade).

Assim os critérios de usabilidade ligados à meta de satisfação têm maior impacto, sendo necessário atenção para o desenvolvimento de sistemas que sanem os problemas apontados de forma a aumentar a participação dos demais fatores para a formação da percepção positiva de uso. Alguns desses fatores foram considerados cruciais pelos próprios usuários para usar ou não usar o sistema de banca digital, sendo que por esse aspecto a usabilidade tem papel motivador para a adoção da plataforma digital.

Considerando os resultados finais, é importante salientar as diferenças demonstradas entre os grupos etários, onde usuários mais jovens foram mais críticos com diversos pontos avaliados, provavelmente pelo maior repertório de uso relacionado aos produtos digitais. Isso mostra a necessidade de entender e atender de forma mais eficiente tal faixa etária que são os futuros consumidores. Levando-se em conta as perspectivas de futuro do mercado, a revista digital e suas plataformas de distribuição necessitarão uma completa revolução no formato (desmaterialização do design tradicional do modelo); produção (as editoras terão que focar sua força de trabalho e expertise na produção de conteúdo nativamente digital e interativo) e distribuição (as bancas digitais precisam ser remodeladas e pensadas na usabilidade para cada dispositivo, considerando a tecnologia e hábitos relacionados ao usuário). Logo acredita-se que isso levará a uma nova definição do modelo de revista e suas plataformas de distribuição, exigindo mais estudos relacionados ao tema.

Acredita-se que academicamente este estudo enriquece o debate sobre como a 
usabilidade e ciências correlatas podem contribuir para a melhoria dos produtos editoriais digitais, abrindo espaço para novas discussões partindo dos métodos e resultados aqui apresentados, como investigações comparativas de uso em dispositivos diversos, estudos baseados na diversidade de grupos amostrais como aqueles que necessitam de recursos de acessibilidade, entre outras possibilidades.

Como resultado prático, acredita-se que os resultados apontam para os itens mais importantes dentro do contexto da usabilidade que podem auxiliar os atores envolvidos na criação e disseminação de publicações digitais - mais especificamente de revistas - a criarem sistemas e projetos mais focados nas necessidades do usuário.

Como consideração final, pode-se dizer que a usabilidade (como um dos diversos fatores que podem levar à adoção do produto) impacta na convergência digital de leitores, principalmente daqueles que ainda possuem afinidade com o modelo cultural de compra e consumo de revistas físicas.

\section{REFERÊNCIAS}

AKOUR, Iman.; ADAMS, Marjorie. Usability evaluation of newspapers websites. International Journal of Business Research and Information Technology, vol. 4, no. 1, 2017, p. 59.

ASSOCIAÇÃO NACIONAL DE EDITORES DE REVISTAS. Factbook ANER 2015: A força do meio revista. Disponível em: http://aner.org.br/factbook/\&gt; Acesso em: 23 set. 2019.

BASILI, Victor; CALDEIRA, Gianluigi; ROMBACH, Dieter. The Goal Question Metric Approach. Encyclopedia of Software Engineering. John Wiley, vol. I, p. 528-532, 1994.

CYBIS, Walter; BETIOL, Adriana Holtz; FAUST, Richard,. Ergonomia e Usabilidade: conhecimentos, métodos e aplicações. $3^{\text {a }}$ ed. São Paulo: Novatec, 2015.

DONYAEE, Mohammad; KLINE, Rex Bryan; PADDA, Harkirat Kaur; SEFFAH, Ahmed. Usability Measurement and Metrics: A consolidated model. Software Qual J, 2006, p. 2514-2519. 2006.

FENSTERSEIFER, Thais Arnold , KRENING, Thiago da Silva ; TEIXEIRA, Fábio Gonçalves ; DA SILVA, Tânia Koltermann; DA SILVA, Régio Pierre Histórias em quadrinhos no contexto dos dispositivos móveis: aspectos teóricos e análise de usabilidade. Revista Brasileira de Design da Informação / Brazilian Journal of Information Design São Paulo, v. 13, n. 1, 2016. p. 22-38.

FREIRE, Marcelo. Jornalismo de revista em tablet: um estudo dos aplicativos para ipad da revista wired e katachi. Portugal. Editora LabCom.IFP. 2016.

GOLFETTO, Ildo Francisco; BALDESSAR, Maria José. Análise de uso e propostas para aprimoramento de edições digitais de revistas através de grupos focais. XII Congreso Latinoamericano de Investigadores de la Comunicación. Peru. 2014.

GRUPO DE MIDIA SÃO PAULO. Mídia Dados 2017. Disponível em: < https://www.gm.org. 
br/midiadados >. Acesso em 10 mar. de 2017.

INSTITUTO VERIFICADOR DE CIRCULAÇÃO. Normas Técnicas. Disponível em:<https:// sag.ivcbrasil.org.br/conteudos/normas_tecnicas/NORMAS_TECNICAS_1_ABRIL_2017. pdf >. Acesso em: 10 mar. 2019.

MEIO \& MENSAGEM. Abril entra em recuperação judicial. 2018. Disponível em: \&lt; http://www.meioemensagem.com.br/home/ultimas-noticias/2018/08/16/editora-escala-encerra-seis-revistas.html\&gt; Acesso em: 20 ago 2018 .

Editora Escala encerra seis revistas. 16 de agosto de 2018. Disponível em: <http://www.meioemensagem.com.br/home/ultimas-noticias/2018/08/16/editora-escala-encerra-seis-revistas.html>. Acesso em: 20 ago 2018b.

NADZIR, Maslinda; HUSSAIN, Azham; MKPOJIOGU, Emmanuel O.C.; ADETUNMBI, Sumayyah;

HASSOONI, Marwah Naeem. Assessing the Comfort in use of a Flipboard Mobile News and Magazine App. International Journal of Innovative Technology and Exploring Engineering (IJITEE), vol. 8, n. 8, Junho, 2019. p. 428-430.

PENTEADO, Cláudia. Revistas atraem renda média maior. Propmark. 2015. Disponível em:<http://propmark.com.br/anunciantes/revistas-atraem-renda-media-maior>. Acesso em: 23 set. 2017.

PREECE, Jenny.; ROGERS, Yvonne.; SHARP, Helen. Interaction Design: beyond human-computer interaction. $5^{a}$ ed. John Wiley \& Sons, Inc., Indianapolis, Indiana, 2019.

RUBIN, Jeffrey; CHRISNELL, Dana. How to plan, design, and conduct effective test. $2^{\mathrm{a}}$ ed. Indiana. Wiley Publishing Inc, 2013.

SANTOS, Maria Luciana Utida.; LICHESKI, Laís. Modelo de ferramenta de análise de revistas digitais. 7th Information Design International Conference. Blucher Design Proceedings, Setembro, 2015. n. 2, vol.2. p. 1715-1719. 2015.

SHNEIDERMAN, Ben; PLAISANT, Catherine; COHEN, Maxine; JACOBS, Steven; ELMQVIST, Niklas DIAKOPOULOS, Nicholas. Designing the user interface: strategies for effective human-computer interaction. $6^{\text {a }}$ ed. University of Maryland, College Park. Pearson Addison Wesley. 2016.

SIVEK, Susan Currie; TOWNSEND, Alyssa. Opportunities and Constraints for Independent Digital Magazine Publishing. Journal of Magazine and New Media Research, vol. 15, n. 1, Spring. 2014.

TULLIS, Thomas; ALBERT William. Measuring the User Experience: Collecting, Analyzing, and Presenting Usability Metrics. Amsterdam. $2^{\mathrm{a}}$ ed. Morgan Kauffman, 2013. 